\title{
Efeitos plastificante e antiplastificante do glicerol e do sorbitol em filmes biodegradáveis de amido de mandioca
}

\section{Plasticizing and antiplasticizing effects of glycerol and sorbitol on biodegradable cassava starch films}

\author{
Angélica Aimoto Shimazu ${ }^{1}$; Suzana Mali²*;Maria Victória Eiras Grossmann ${ }^{3}$
}

\section{Resumo}

\begin{abstract}
Neste trabalho foram estudados os efeitos plastificante e antiplastificante do glicerol e do sorbitol sobre as propriedades de sorção de água e mecânicas de filmes de amido de mandioca . Os filmes foram produzidos por casting empregando-se amido de mandioca ( $3 \mathrm{~g} / 100 \mathrm{~g}$ de solução filmogênica) e diferentes concentrações de glicerol ou sorbitol $(0,5,10,15,30$ e $40 \mathrm{~g} / 100 \mathrm{~g}$ de amido). Glicerol e sorbitol apresentaram efeito antiplastificante quando empregados em baixas concentrações $(\leq 15 \mathrm{~g} / 100 \mathrm{~g}$ amido $)$ e sob baixos valores de atividade de água $(\leq 0,58)$. O efeito antiplastificante pode ser demonstrado pelo decréscimo da hidrofilicidade e da flexibilidade dos filmes nestas condições. Em concentrações mais elevadas de plastificante e sob maiores atividades de água, os plastificantes empregados exerceram o efeito esperado de plastificação.
\end{abstract}

Palavras-chave: Antiplastificação, amido de mandioca

\begin{abstract}
In this work were studied the plasticizing - antiplasticizing effects of glycerol and sorbitol on moisture sorption and mechanical properties of cassava starch films. Films were produced by casting with cassava $\operatorname{starch}(3 \mathrm{~g} \mathrm{starch} / 100 \mathrm{~g}$ filmogenic solution) and different concentrations of glycerol or sorbitol $(0,5,10,15,30$ and $40 \mathrm{~g} / 100 \mathrm{~g}$ starch). Glycerol and sorbitol acted as antiplasticizers when used at a low concentration $(\leq 15 \mathrm{~g} / 100 \mathrm{~g}$ starch $)$ and low values of water activity $(\leq 0,58)$. The antiplasticizing effect could be demonstrated by the decrease in hydrophilicity and in flexibility of the films at these conditions. At higher concentrations and higher water activity values, the employed plasticizers exerted its plasticizing effect.
\end{abstract}

Key words: Antiplasticization, cassava starch

1 Aluna de Graduação do Curso de Farmácia da Universidade Estadual de Londrina - Iniciação Científica.

2 Farmacêutica - Bioquímica, Doutora em Ciência de Alimentos e Bolsista CAPES - PRODOC do Departamento de Ciência e Tecnologia de Alimentos e Medicamentos, CCA, UEL. E-mail: smali@uel.br

3 Docente do Programa de Mestrado e Doutorado em Ciência de Alimentos do DCTA, CCA, UEL.

* Autor para correspondência 


\section{Introdução}

Nos últimos anos tem havido um grande interesse na pesquisa e desenvolvimento de materiais de embalagem biodegradáveis no sentido de diminuir o acúmulo de resíduos plásticos no meio ambiente. $\mathrm{O}$ Brasil produz cerca de 240 mil toneladas de lixo por dia, número inferior ao produzido nos EUA (607.000 t./dia), porém muito superior a países como Alemanha (85.000 t./dia) e a Suécia (10.400 t./dia) e, no Brasil, a maior parte destes resíduos vai para lixões a céu aberto (VILPOUX; AVEROUS, 2003).

A biodegradação é um processo natural e complexo onde compostos orgânicos, pelo intermédio de mecanismos bioquímicos, são convertidos em simples compostos mineralizados e, então, redistribuídos no meio ambiente, através do ciclo elementar, tal como o do carbono, nitrogênio e enxofre (SALAME, 1986). Em síntese, a biodegradação de um polímero é o processo intrínseco pelo qual microorganismos e suas enzimas consomem este polímero como fonte de nutrientes, em condições normais de umidade, temperatura e pressão; os polímeros melhor adaptados à biodegradação completa são os naturais, aqueles hidrolisáveis a $\mathrm{CO}_{2}$ e $\mathrm{H}_{2} \mathrm{O}$, ou $\mathrm{a} \mathrm{CH}_{4}$ e os polímeros sintéticos que possuam estruturas próximas aos naturais (LIMA, 2004).

Em meados dos anos 70, as pesquisas se voltaram para a introdução de amido a matrizes poliméricas sintéticas, na proporção de 5 a $20 \%$, levando à obtenção de plásticos considerados biofragmentáveis, mas não totalmente biodegradáveis. Nos últimos anos, há o interesse no desenvolvimento de materiais termoplásticos compostos essencialmente por polímeros biodegradáveis, tais como os amidos e as proteínas (SOUZA; ANDRADE, 2000).

Inúmeros estudos têm sido publicados sobre caracterização das propriedades funcionais de filmes a base de amido (BADER; GORITZ, 1994a, 1994b, 1994c; GARCIA; MARTINO; ZARITZKY, 1998, 2000; MALI; GROSSMANN, 2003; MALI et al., 2002; 2004), principalmente porque o amido é uma matéria-prima abundante e disponível em todo o mundo, apresenta muitas possibilidades de modificação química, física ou genética e origina filmes e revestimentos resistentes.

O amido é formado por dois tipos de polímeros de glicose: a amilose e a amilopectina, com estruturas e funcionalidade diferentes. A amilose é um polímero linear com unidades de $\mathrm{D}$-glicose ligadas por ligações $\alpha-(1 \rightarrow 4)$, com grau de polimerização de 200 a 3000, dependendo da fonte do amido. A amilopectina é um polímero altamente ramificado, com unidades de Dglicose ligadas através de ligações $\alpha-(1 \rightarrow 4)$ e as ramificações em $\alpha-(1 \rightarrow 6)$ (ELLIS et al., 1998). Variações nas proporções entre estes componentes e, em suas estruturas e propriedades, podem resultar em grânulos de amido com propriedades físicoquímicas e funcionais muito diferentes, que podem afetar as suas aplicações industriais.

A aplicação do amido na confecção de biofilmes se baseia nas propriedades químicas, físicas e funcionais da amilose para formar géis e na sua capacidade para formar filmes (YOUNG, 1984). As moléculas de amilose em solução, devido à sua linearidade, tendem a se orientar paralelamente, aproximando-se o suficiente, para que se formem ligações de hidrogênio entre hidroxilas de polímeros adjacentes. Como resultado, a afinidade do polímero por água é reduzida, favorecendo a formação de pastas opacas e filmes resistentes (WURZBURG, 1986).

Como os filmes confeccionados exclusivamente por amido são pouco flexíveis e quebradiços e apresentam baixa maquinabilidade, ou seja, se adequam com dificuldade aos processamentos convencionais para a produção de embalagens, a introdução de aditivos às matrizes poliméricas é necessária. A questão da rigidez pode ser resolvida através da adição de plastificantes, que melhoram as propriedades mecânicas dos filmes (GONTARD; GUILBERT; CUQ, 1993).

Os plastificantes devem ser compatíveis com o biopolímero e, os mais estudados em combinação com os filmes de amido são os polióis, como o glicerol e o sorbitol, materiais que interagem com as cadeias 
de amido, aumentando a mobilidade molecular e, conseqüentemente, a flexibilidade dos seus filmes. Outro efeito é o aumento da hidrofilicidade e permeabilidade ao vapor de água dos filmes plastificados, já que a maioria dos plastificantes empregados em filmes de amido tem caráter hidrofílico (MALI et al, 2004).

Os plastificantes são geralmente adicionados na proporção de 10 a $60 \mathrm{~g} / 100 \mathrm{~g}$ matéria seca, dependo do grau de rigidez do material (GONTARD; GUILBERT; CUQ, 1993). No entanto, dependendo da concentração em que são empregados, podem causar um efeito chamado antiplastificante, isto é, ao invés de aumentar a flexibilidade e hidrofilicidade, podem causar um efeito contrário (GAUDIN et al., 1999; 2000). Geralmente, isto ocorre quando são empregadas pequenas concentrações de plastificante (abaixo $20 \mathrm{~g} / 100$ amido), então o plastificante interage com a matriz polimérica mas não está em quantidade suficiente para aumentar a mobilidade molecular, fenômeno também dependente das condições de armazenamento (LOURDIN et al., 1997). Diante disto, os objetivos do presente trabalho foram estudar o efeito plastificante e antiplastificante do glicerol e do sorbitol em filmes plásticos biodegradáveis de amido de mandioca, caracterizando os filmes produzidos quanto as suas propriedades de sorção de água e propriedades mecânicas em função da concentração e do tipo de plastificante.

\section{Material e Métodos}

\section{Produção dos filmes}

Os filmes foram confeccionados com amido de mandioca ( $3 \mathrm{~g}$ de amido/ $100 \mathrm{~g}$ de solução filmogênica) empregando-se dois tipos diferentes de plastificantes (glicerol ou sorbitol) em diferentes concentrações ( 0 , $5,10,15,30$ e $40 \mathrm{~g}$ de plastificante/ $100 \mathrm{~g}$ de amido), segundo técnica do tipo casting. As soluções filmogênicas foram aquecidas de $30 \mathrm{a} 95^{\circ} \mathrm{C}$, mantidas a $95^{\circ} \mathrm{C}$ por 10 minutos, empregando-se viscógrafo
Brabender Pt 100 (Duisburg - Alemanha). Em seguida, foram espalhadas em placas de acrílico (10 x $20 \mathrm{~cm}) 100 \mathrm{~g}$ de cada solução filmogênica e o material foi seco em estufa com circulação e renovação de ar (Tecnal 394-3 / Piracicaba - SP), a $40^{\circ} \mathrm{C}$ até peso constante. Os filmes foram condicionados, durante 48 horas, em dessecadores, sob umidade relativa de $64 \%$ e temperatura ambiente $\left(25^{\circ} \mathrm{C} \pm 2\right)$, antes das análises.

\section{Caracterização dos filmes}

\section{Espessura}

A espessura dos filmes foi determinada utilizandose um micrômetro manual (resolução $0,001 \mathrm{~mm}$, Mitutoyo - São Paulo - SP). A espessura final foi a média aritmética de 10 medidas aleatórias sobre a área do filme.

\section{Perfil de sorção de umidade}

As isotermas de adsorção dos filmes de amido de mandioca foram determinadas, em triplicata, de acordo com procedimentos descritos por SPIESS e WOLF (1993), com algumas modificações. As amostras foram secas em estufa com circulação de ar, por 7 dias, na presença de pentóxido de fósforo $\left(\mathrm{P}_{2} \mathrm{O}_{5}\right)$. Então, amostras da ordem de 0,5 $\mathrm{g}$ foram pesadas em pesa-filtros de alumínio de $10 \mathrm{~mL}$, previamente tarados, que foram colocados em dessecadores contendo diferentes soluções saturadas de sais (Tabela 1), varrendo a faixa de atividade de água de 0,11 a 0,90 , sob temperatura de $25^{\circ} \mathrm{C}$. Após o seu fechamento, os dessecadores foram vedados com a ajuda de uma cera de silicone e colocados em estufa incubadora para B.O.D., até que as amostras tivessem atingido umidade de equilíbrio. A umidade de equilíbrio das amostras foi determinada através de método de secagem em estufa a $105^{\circ} \mathrm{C}$ (ASSOCIATION OF OFICIAL ANALYTICAL CHEMISTS, 1995). 
Tabela 1. Atividade de água das soluções saturadas de sais empregadas para determinação de isotermas de absorção.

\begin{tabular}{lc}
\hline Sal & Atividade de água $\left.\mathbf{( 2 5}^{\mathbf{0}} \mathbf{C}\right)$ \\
\hline Cloreto de lítio & 0,11 \\
Cloreto de magnésio & 0,33 \\
Brometo de sódio & 0,58 \\
Cloreto de sódio & 0,75 \\
Cloreto de bário & 0,90 \\
\hline
\end{tabular}

\section{Propriedades mecânicas}

As propriedades de tração foram determinadas em analisador de textura TA.TX2 Stable Micro Systems (Surrey -Inglaterra), acoplado de célula de carga de $5 \mathrm{~kg}$, empregando-se metodologia ASTM D-882-91 (AMERICAN SOCIETY FOR TESTING AND MATERIAL, 1995). As amostras foram cortadas nas dimensões de $100 \mathrm{~mm}$ de comprimento e $25,4 \mathrm{~mm}$ de largura e ajustadas às garras do equipamento. A distância inicial entre as garras foi de $50 \mathrm{~mm}$ e a velocidade de tração de $500 \mathrm{~mm} / \mathrm{min}$. As propriedades de tração determinadas foram: resistência máxima à tração $(\mathrm{MPa})$ e alongamento na ruptura (\%). Foram realizadas 5 medidas para cada amostra.

\section{Análise estatística}

Para análise estatística dos resultados obtidos foi empregado programa computacional Statistica versão 5.0 (Statsoft - Oklahoma - USA). Foram realizadas análises de variância (ANOVA) e teste de Tukey (nível de significância de 5\%) para comparação de médias.

\section{Resultados e Discussão}

Todos os filmes de amido de mandioca com plastificante (glicerol e sorbitol) se mostraram contínuos, sem fraturas ou rupturas após a secagem; os filmes sem plastificante se mostraram mais quebradiços. $\mathrm{O}$ aspecto visual dos filmes não foi afetado pelos diferentes teores de plastificante e, de uma maneira geral, os filmes apresentaram-se transparentes, incolores e com bom aspecto.

A manuseabilidade dos filmes foi excelente ou boa na maioria dos filmes, com exceção dos filmes com $40 \%$ de glicerol; isto ocorreu devido à dificuldade em serem destacados dos suportes sem rasgar, porém, após retirados das placas, todos os filmes puderam ser manipulados sem qualquer risco de ruptura. Estes filmes se mostraram mais aderidos aos suportes, certamente, devido à maior proporção glicerol : amido empregada em sua formulação, o quê conferiu uma maior adesividade às amostras. MALI et al. (2005) relatam resultados similares para filmes de amido de mandioca plastificados com glicerol.

A espessura dos filmes variou de 0,07 a 0,10 mm; filmes sem plastificante apresentaram espessura de $0,07 \mathrm{~mm}$ e, à medida que o teor de plastificante aumentou, as espessuras dos filmes chegaram a 0,10 $\mathrm{mm}$. Como foi colocada a mesma quantidade de solução filmogênica nas placas para a formação dos filmes com as diferentes formulações, filmes com maior teor de plastificante, que continham maior teor de sólidos secos apresentaram a maior espessura.

\section{Perfil de sorção de umidade}

As isotermas de adsorção e a sorção de umidade em função do teor de glicerol estão apresentadas nas Figuras 1 e 2. Pode-se observar que as variações na hidrofilicidade das amostras foram dependentes tanto do teor de glicerol como da atividade de água dos filmes. A umidade de equilíbrio das amostras aumentou à medida que se aumentou a atividade de água dos filmes (Figuras 1 e 2). Sob atividade de água de 0,11 , as amostras não plastificadas se mostraram mais hidrofilicas que todas as amostras plastificadas com diferentes níveis de glicerol ( 5 a $40 \mathrm{~g} / 100 \mathrm{~g}$ amido), sob Aa de 0,33 e 0,58 , apenas os filmes com 30 e $40 \mathrm{~g}$ glicerol/ $100 \mathrm{~g}$ amido foram mais hidrofílicos que os não plastificados e, sob 0,90 de Aa, todos os filmes plastificados se mostraram mais hidrofilicos que os não plastificados (Figuras 1 e 2). 


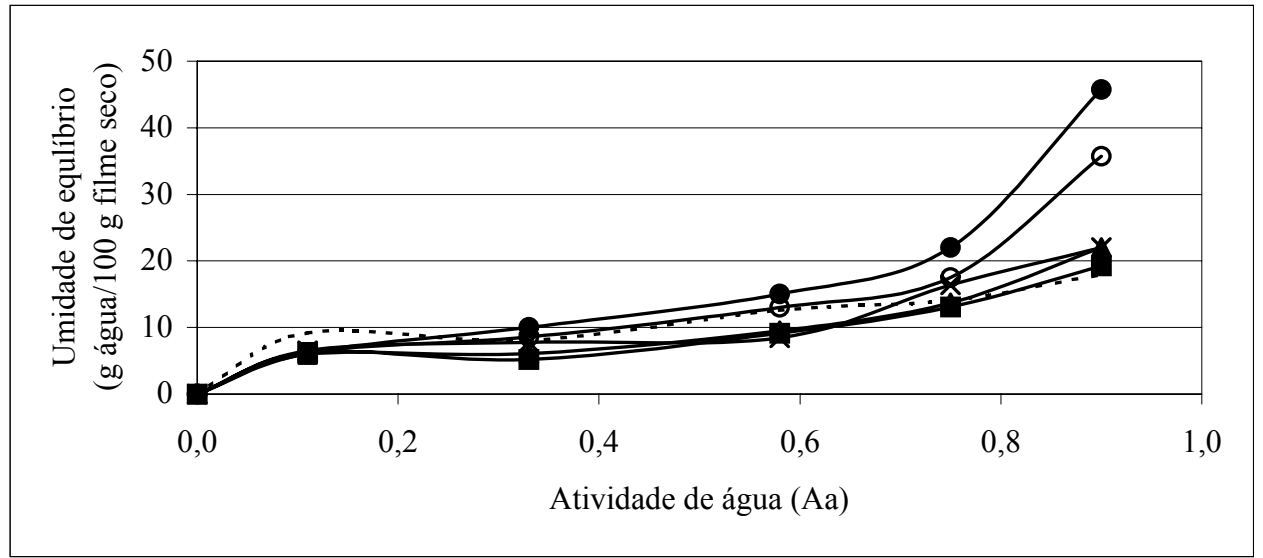

Figura 1. Isoterma de adsorção de filmes de filmes de amido de mandioca plastificados com diferentes teores de glicerol: (—) $0 \mathrm{~g} / 100 \mathrm{~g}$ amido, ( 1 ) $5 \mathrm{~g} / 100 \mathrm{~g}$ amido, ( • ) $10 \mathrm{~g} / 100 \mathrm{~g}$ amido, (x) $15 \mathrm{~g} / 100 \mathrm{~g}$ amido, (o) $30 \mathrm{~g} / 100 \mathrm{~g}$ amido $\mathrm{e}(\bullet) 40 \mathrm{~g} / 100 \mathrm{~g}$ amido.

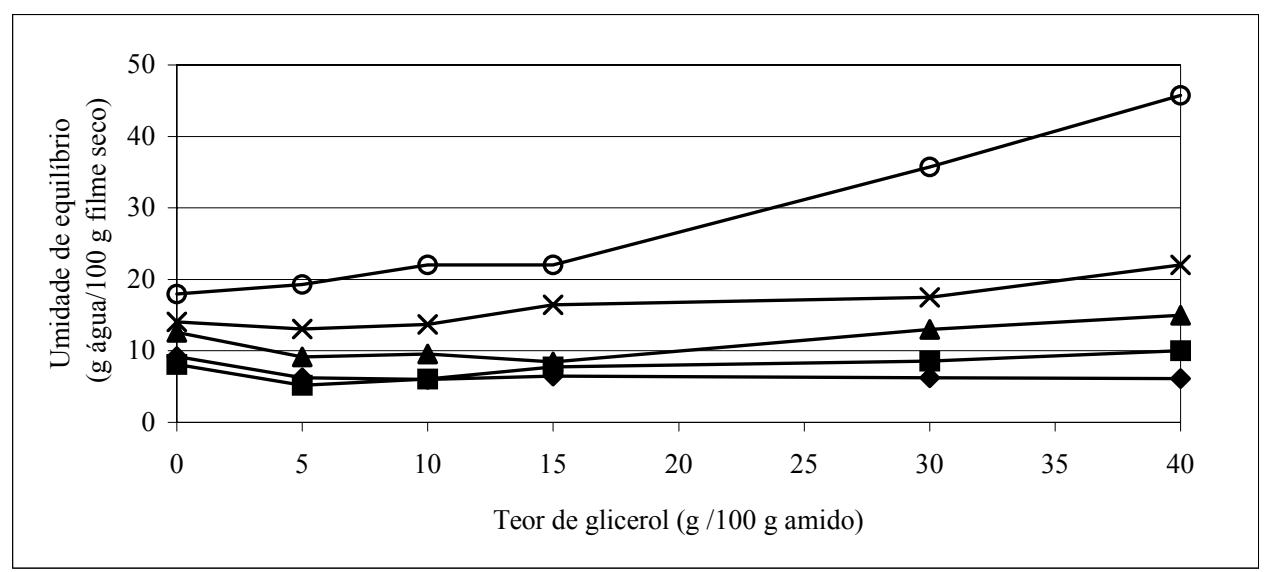

Figura 2. Sorção de umidade em função do teor de glicerol de filmes de amido de mandioca sob diferentes atividades de água: $(\bullet) 0,11,(\boldsymbol{\square}) 0,33,(\bullet) 0,58,(x) 0,75$ e (o) 0,90 .

O glicerol é um plastificante hidrofílico bastante empregado, que interage com as cadeias de amido, aumentando a mobilidade molecular e, conseqüentemente, a hidrofilicidade e a flexibilidade dos filmes plastificados (MALI et al, 2004). Neste trabalho, quando empregado sob baixas concentrações ( $\leq 15 \mathrm{~g} / 100 \mathrm{~g}$ amido) e em filmes com baixos valores de $\mathrm{Aa}(\leq 0,58)$, o glicerol exerceu um efeito contrário, de decréscimo da hidrofilicidade, já relatado por outros autores, que estudaram este plastificante em diferentes combinações e com outros tipos de amido, como efeito antiplastificante (LOURDIN et al.1997; GAUDIN et al., 1999; 2000; MALI et al., 2005; CHANG; KARIM; SEOW,
2006). De acordo com LOURDIN et al. (1997), o efeito antiplastificante pode ser evidenciado pelo decréscimo da hidrofilicidade sob baixos valores de Aa e baixos teores de plastificante, e é um indicativo de que interações mais fortes entre o plastificante e o biopolímero (amido) estejam ocorrendo, neste caso, interações do tipo pontes de hidrogênio, que induzem a um decréscimo da mobilidade molecular e da capacidade de ligação com a água. Relatam, ainda, que para materiais com umidades de equilíbrio inferiores a $10 \%$ (como é o caso dos filmes deste trabalho que foram plastificados com concentrações $\leq 15 \mathrm{~g}$ glicerol $/ 100 \mathrm{~g}$ amido e $\mathrm{Aa} \leq 0,58$ ), as interações polímero - água são mais compactas que 
as polímero-polímero e, que acima de $10 \%$ de umidade, uma rede polimérica mais fraca é formada devido às interações água-água.

Quando se observa a sorção de água em função do teor de glicerol (Figura 2), pode-se notar que todos filmes com atividade de água $\leq 0,58$ apresentaram um comportamento similar, ou seja, um decréscimo na capacidade de hidratação com aumento do teor de glicerol, até um mínimo e, então, um aumento; nestas condições, filmes com $15 \%$ de glicerol apresentaram hidratação mínima. Estes resultados são semelhantes aos observados por outros autores (LOURDIN et al., 1997; CHANG; KARIM; SEOW, 2006).

Nos filmes plastificados com sorbitol a umidade de equilíbrio das amostras também aumentou à medida que se aumentou a atividade de água dos filmes, que apresentaram menores umidades de equilíbrio que os filmes com glicerol, em todos os valores de Aa (Figuras 3 e 4). Esta diferença está relacionada com as diferenças estruturais entre os dois plastificantes e com o tipo de interação que fazem com a rede polimérica de amido. Glicerol e sorbitol são polióis, no entanto, o glicerol possui 3 carbonos ligados a 3 hidroxilas, e o sorbitol, 6 carbonos ligados a 6 hidroxilas, o que faz com que tenha uma maior capacidade de interação com as moléculas de amido, dando menor mobilidade às cadeias formadoras da matriz dos filmes e, conseqüentemente, diminuindo a sua capacidade de ligação com a água. As diferenças entre os plastificantes podem ser relacionadas, também, com os seus pesos moleculares (PM), plastificantes com menor PM, como o glicerol, exercem plastificação mais efetiva que os de maior PM. Além de tudo isto, o glicerol apresenta maior hidrofilicidade que o sorbitol (SOTHORNVIT; KROCHTA, 2001). Em função de todas estas características, o glicerol é tido como um plastificante mais efetivo que o sorbitol (MALI et al., 2005).

Os filmes plastificados com diferentes níveis de sorbitol ( $5 \mathrm{a} 40 \mathrm{~g} / 100 \mathrm{~g}$ de amido) e sob atividade de água $\leq 0,58$ foram menos hidrofílicos que os filmes não plastificados (Figura 3), evidenciando-se nestas condições o efeito antiplastificante do sorbitol; o efeito esperado de plastificação do sorbitol, isto é, o aumento da hidrofilicidade só pode ser observado em maiores valores de Aa.

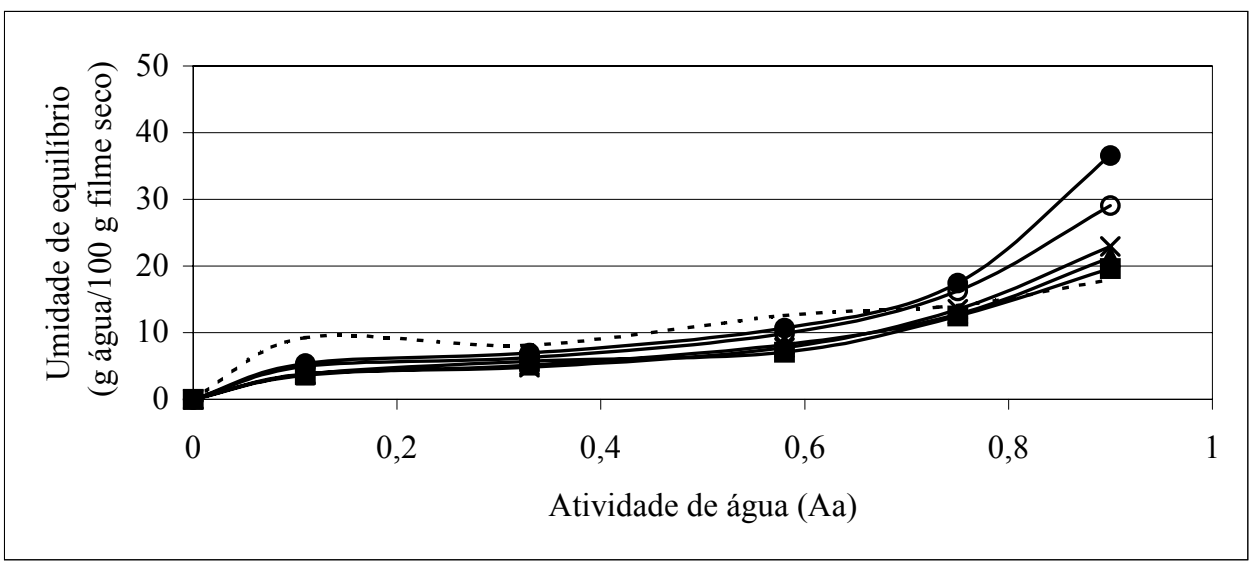

Figura 3. Isoterma de adsorção de filmes de filmes de amido de mandioca plastificados com diferentes teores de sorbitol: (—) $0 \mathrm{~g} / 100 \mathrm{~g}$ amido, ( 1 ) $5 \mathrm{~g} / 100 \mathrm{~g}$ amido, ( • ) $10 \mathrm{~g} / 100 \mathrm{~g}$ amido, (x) $15 \mathrm{~g} / 100 \mathrm{~g}$ amido , (o) $30 \mathrm{~g} / 100 \mathrm{~g}$ amido (•) $40 \mathrm{~g} / 100 \mathrm{~g}$ amido. 


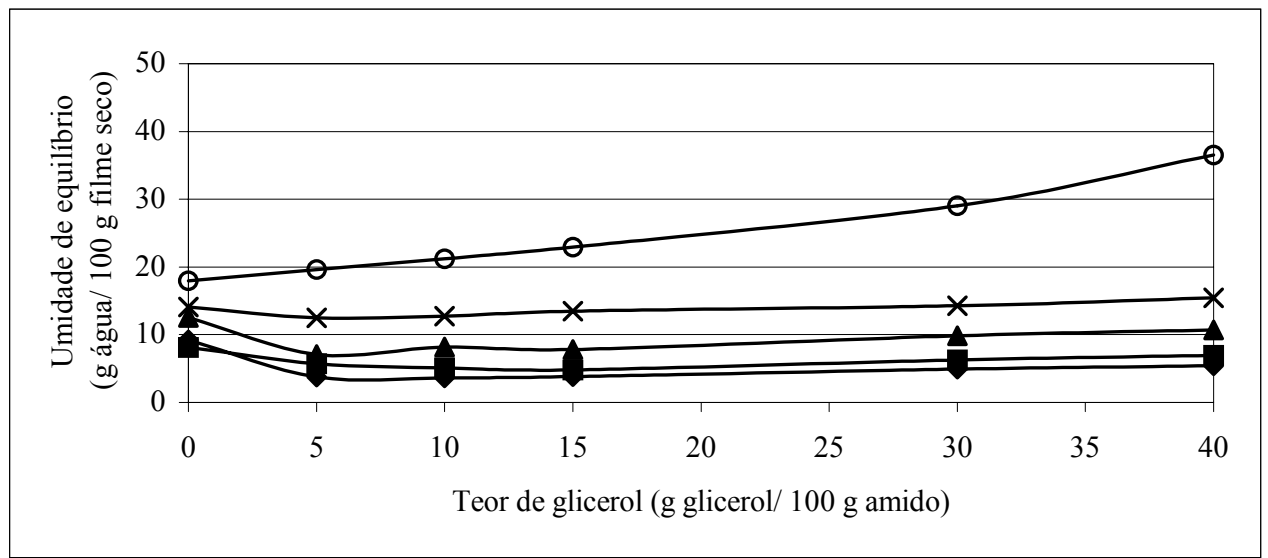

Figura 4. Sorção de umidade em função do teor de sorbitol de filmes de amido de mandioca sob diferentes atividades de água: $(\bullet) 0,11,(\boldsymbol{\square}) 0,33,(\bullet) 0,58,(\mathrm{x}) 0,75$ e (o) 0,90.

\section{Propriedades mecânicas}

Tanto os filmes plastificados com glicerol, quanto os com sorbitol, apresentaram um decréscimo da resistência máxima à tração (RMT) com o aumento da atividade de água, isto é, os filmes com Aa de 0,11 foram mais resistentes enquanto que os filmes com 0,90 foram menos resistentes (Figura $5 \mathrm{a}, \mathrm{b}$ ). Este comportamento pode ser observado em estudos realizados por outros autores (MALI et al., 2005; CHANG; KARIM; SEOW, 2006) e é esperado para materiais hidrofílicos como os filmes de amido, que podem sofrer plastificação pela água.

$\mathrm{O}$ efeito dos outros plastificantes (glicerol e sorbitol) sobre as propriedades mecânicas é mais complexo que o da água. Pode-se observar, de uma forma geral, que os filmes plastificados com glicerol apresentaram menor RMT que os com sorbitol (Figura 5 a,b) e uma tendência de queda na resistência à medida que este plastificante foi adicionado, mesmo nos menores teores. Filmes plastificados com sorbitol sob concentrações de 5, 10 e $15 \mathrm{~g}$ sorbitol/100 de amido e Aa de 0,11 a 0,58 foram mais resistentes que os filmes não plastificados. Provavelmente, este efeito do sorbitol em baixas concentrações e baixas atividades de água é mais um indicativo do seu efeito antiplastificante, isto é, ao invés de aumentar a mobilidade molecular entre as cadeias de amido, se liga fortemente ás cadeias de amido, aumentando o grau de interação, e conseqüentemente, a resistência mecânica e rigidez destes materiais (GAUDIN et. al, 1999).

Nos filmes plastificados com glicerol, o aumento da elongação (flexibilidade), em relação aos filmes não plastificados foi dependente da Aa dos filmes (Figura 6a). Sob Aa de 0,11 e 0,33, apenas filmes com $40 \mathrm{~g}$ glicerol $/ 100 \mathrm{~g}$ de amido apresentaram aumento significativo (teste de Tukey, $\mathrm{p} \leq 0,05$ ) na elongação (Figura 6a). Sob Aa $\geq 0,58$ podem ser observados aumentos significativos (teste de Tukey, $p \leq 0,05$ ) na elongação a partir de concentrações de glicerol de $30 \mathrm{~g} /$ $100 \mathrm{~g}$ de amido. Filmes com maiores Aa foram mais flexíveis, chegando a um máximo de elongação sob Aa de 0,75 e, nesta Aa, um aumento significativo na flexibilidade foi observado a partir de $15 \mathrm{~g}$ glicerol $/ 100 \mathrm{~g}$ de amido; filmes com Aa de 0,90 foram menos flexíveis devido à sua pouca resistência mecânica (Figura 6a).

Nos filmes com sorbitol, a elongação também foi dependente das condições de armazenamento; em filmes com $\mathrm{Aa} \leq 0,33$, a flexibilidade não se alterou em função do teor de sorbitol, sob Aa de 0,58 , apenas os filmes com $40 \mathrm{~g}$ sorbitol $/ 100 \mathrm{~g}$ de amido apresentaram aumento significativo (teste de Tukey, $\mathrm{p} \leq$ 0,05) na elongação em relação aos não plastificados e, sob $\mathrm{Aa} \geq 0,75$, os filmes com 30 e 40 $\mathrm{g}$ sorbitol $/ 100 \mathrm{~g}$ de amido foram mais flexíveis que os não plastificados (Figura 6b). 

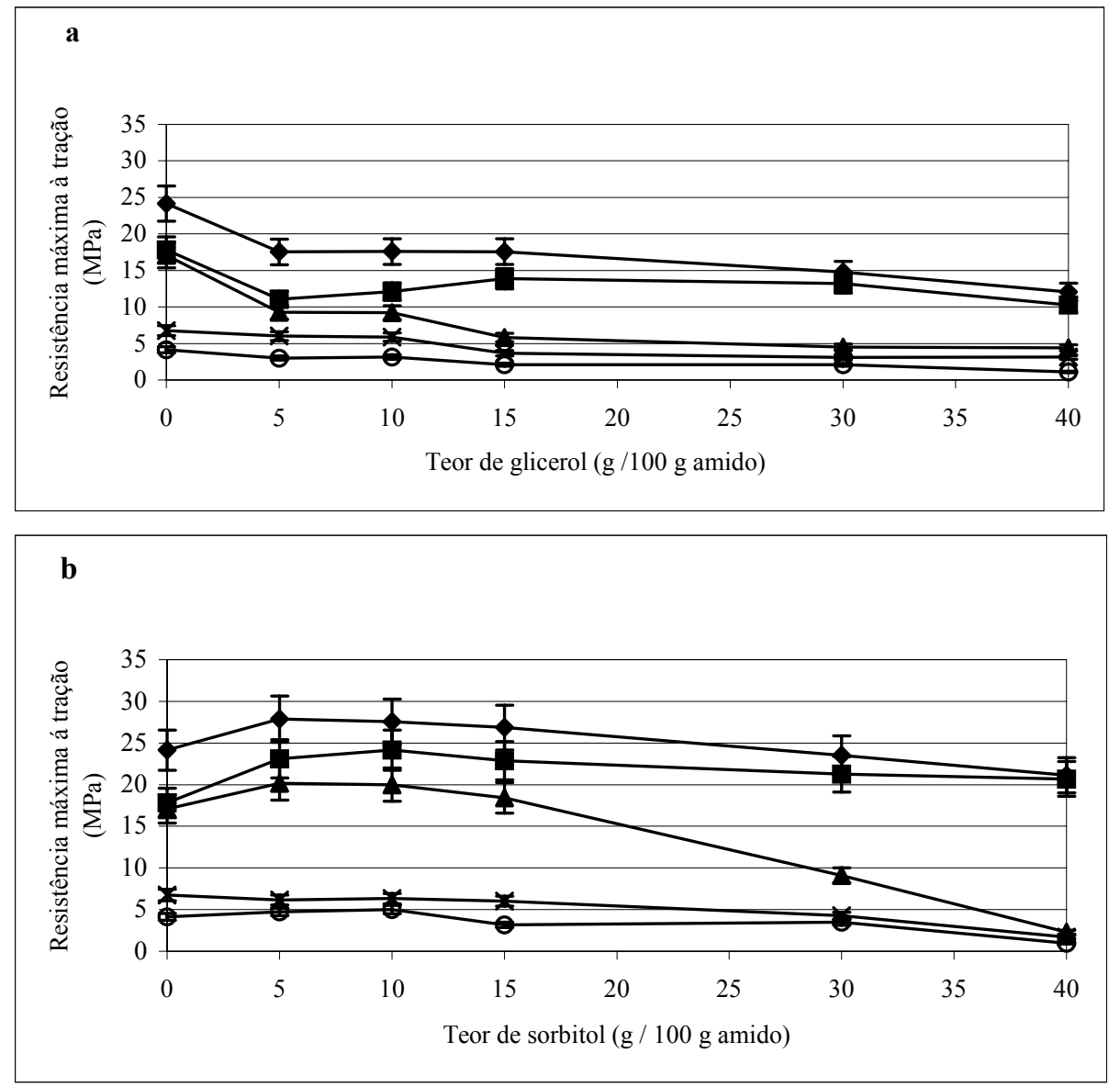

Figura 5. Resistência máxima à tração de filmes de amido de mandioca plastificados com diferentes níveis de glicerol (a) e sorbitol (b), sob diferentes atividades de água: (• ) 0,11, ( $)$ ) 0,33, (• ) 0,58, (x) 0,75 e (o) 0,90.

Este efeito dos plastificantes (glicerol e sorbitol), quando empregados em baixas concentrações e baixos valores de Aa, de não aumentar significativamente a flexibilidade das amostras, está de acordo com os dados obtidos neste trabalho e, também, por outros autores (LOURDIN et al, 1997; GAUDIN et al., 1999; 2000).
De uma forma geral, os filmes plastificados com glicerol se mostraram mais flexíveis que os com sorbitol, apresentando, em todos os valores de Aa, maiores valores de elongação (Figura 6 a,b); este resultado é mais um indicativo da maior efetividade do glicerol como plastificante, o que já havia sido evidenciado neste trabalho e, também, relatado em outros estudos com filmes confeccionados com outros tipos de biopolímeros hidrofílicos, como a lactoglobulina (SOTHORNVIT; KROCHTA, 2001) e a proteína de soja (CHO; RHEE, 2002). 

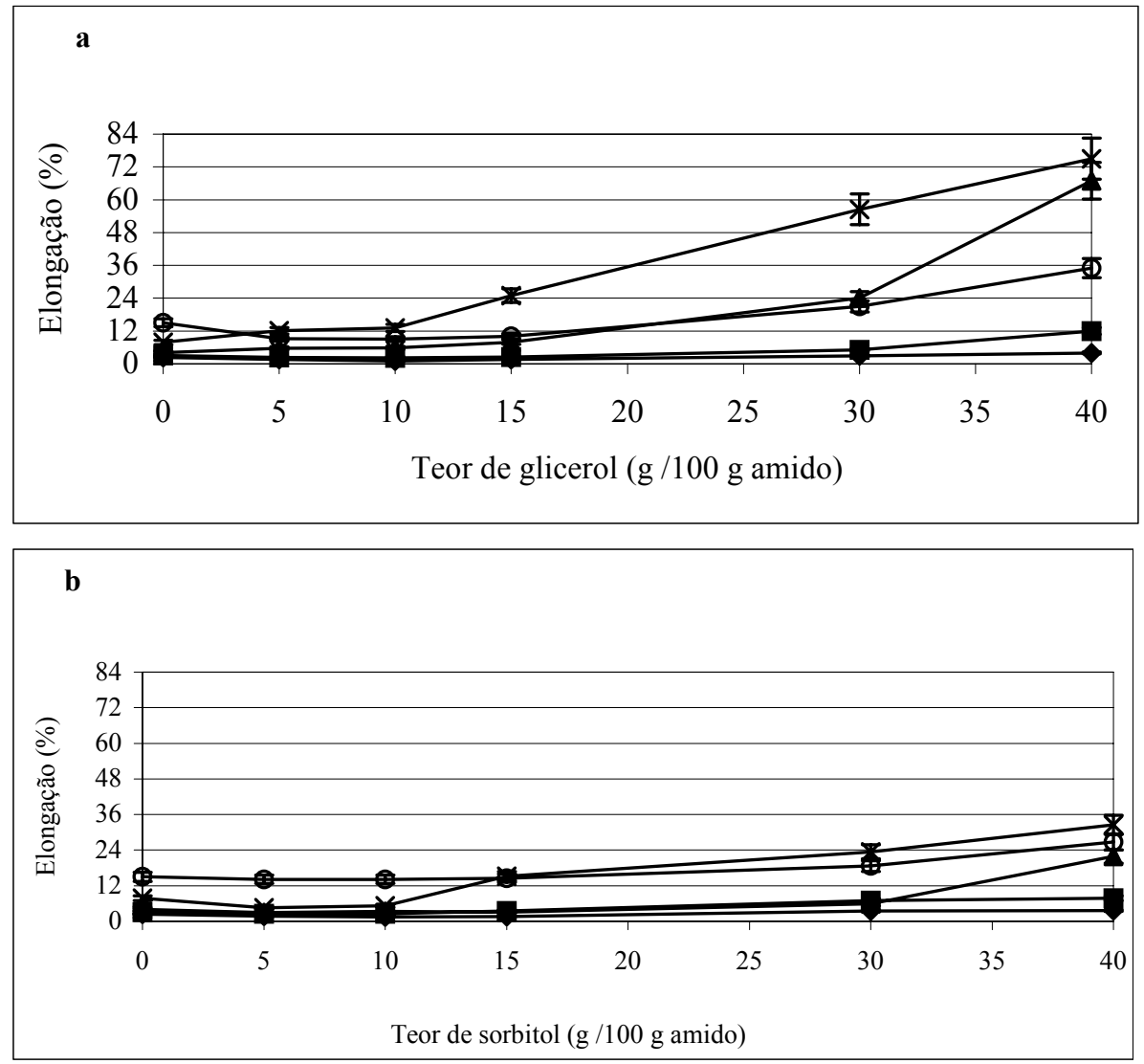

Figura 6. Elongação de filmes de amido de mandioca plastificados com diferentes níveis de glicerol (a) e sorbitol (b), sob diferentes atividades de água: $(\bullet) 0,11,(\boldsymbol{\square}) 0,33,(\bullet)$ ) 0,58, (x) 0,75 e (o) 0,90.

\section{Conclusões}

As condições de armazenamento (Aa) e os teores de glicerol e sorbitol empregados se mostraram fatores importantes na determinação do efeito plastificante ou antiplastificante do glicerol e sorbitol. Sob baixos valores de atividade de água, filmes com baixos teores de plastificante, se mostraram menos hidrofílicos e menos flexíveis que os filmes não plastificados, sugerindo um efeito antiplastificante do glicerol e do sorbitol.

Comparando-se glicerol e sorbitol, pode-se observar que o glicerol exerceu plastificação mais efetiva, tornando os filmes mais hidrofílicos (por aumentar a sua capacidade de interação com a água) e mais flexíveis.

\section{Agradecimentos}

Ao Programa Capes/ProDoc e ao PROIC (UEL).

\section{Referências}

ASSOCIATION OF OFICIAL ANALYTICAL CHEMISTS (AOAC). Official Methods of Analysis. Washington (USA): AOAC, 1995.

AMERICAN SOCIETY FOR TESTING AND MATERIAL (ASTM). Standard Test Methods for Tensile Properties of Thin Plastic Sheeting. ASTM D882-91. Philadelphia (USA): ASTM, 1995.

BADER, H. G.; GÖRITZ, D. Investigations on high amylose corn starch films. Part 1: Wide angle X-ray scattering (WAXS). Starch/Stärke, Weinheim, v.46, n.6, p.229-232, 1994a. 
. Investigations on high amylose corn starch films. Part 2: Water vapor sorption. Starch/Stärke, Weinheim, v.46, n.7, p.249-252, 1994b.

. Investigations on high amylose corn starch films. Part 3: Stress strain behavior. Starch/Stärke, Weinheim, v.46, n.11, p.435-439, 1994c.

CHANG, Y. P.; KARIM, A. A.; SEOW, C. C. Interactive plasticizing-antiplasticizing effects of water and glycerol on the tensile properties on tapioca starch films. Food Hydrocolloids, Oxford, v.20, p.1-8, 2006.

CHO, S. Y.; RHEE, C. Sorption characteristics of soy protein films and their relation to mechanical properties. Lebenmittel Wissenchaft und Technology, London, v. 35, p.151-157, 2002.

ELLIS, R.P.; COCHRANE, M. P.; DALE, M. F. B.; DUFFUS, C. M.; LYNN, A.; MORRISON, I. M.; PRENTICE, R. D. M.; SWANSTON, J. S.; TILLER, S. A. Starch production and industrial use (Review). Journal of Science Food and Agriculture, London, v.77, n.3, p.289-311, 1998.

GARCIA, M. A.; MARTINO, M. N.; ZARITZKY, N. E. Starch - base coatings: effect on refrigerated strawberry (Fragaria ananassa) quality. Journal of Food Science and Agriculture, v.76, p.411-420, 1998.

GARCIA, M. A.; MARTINO, M. N.; ZARITZKY, N. E. Microstructural characterization of plasticized starchbased films. Starch/Stärke, v.52, n.4, p.118-124, 2000.

GAUDIN, S.; LOURDIN, D.; LE BOTLAN, D.; ILARI, J. L. Colonna P. Plasticisation and mobility in starch-sorbitol films. Journal of Cereal Science, London, v.29, p.273-284, 1999.

GAUDIN, S.; LOURDIN, D.; FORSSELL, P. M.; COLONNA, P. Antiplasticisation and oxygen permeability of starchsorbitol films. Carbohydrate Polymers, Barking, v.43, p.33$37,2000$.

GONTARD, N.; GUILBERT, S.; CUQ, J. L. Water and glycerol as plasticizers affect mechanical and water vapor barrier properties of an edible wheat gluten film. Journal of Food Science, Chicago, v.58, n.1, p.206-211, 1993.

LIMA, S. L. T. Reciclagem e biodegradação de plásticos. Revista Científica do IMAPES, Sorocaba, p.28-34, 2004.

LOURDIN, D.; COIGNARD, L.; BIZOT, H.; COLONNA, P. Influence of equilibrium relative humidity and plasticizer concentration on the water content and glass transition of starch materials. Polymer: The Chemistry, Physics And Technology Of High Polymer, London, v.38, n.21, p.54015406, Oct. 1997.
MALI, S.; GROSSMANN, M. V. E. Effects of yam starch films on storability and quality of fresh strawberries (Fragaria ananassa). Journal of Agricultural and Food Chemistry, Washington, p.7055-7011, 2003.

MALI, S., GROSSMANN, M. V. E., GARCÍA, M. A., MARTINO, M. M.; ZARITZKY, N. E. Barrier, mechanical and optical properties of plasticized yam starch films. Carbohydrate Polymers, Barking, v.56, p.129-135, 2004.

. Microstructural characterization of yam starch films. Carbohydrate Polymers, Barking, v.50, p.379-386, 2002.

MALI, S.; SAKANAKA, L. S.; YAMASHITA, F.; GROSSMANN, M. V. E. Water sorption and mechanical properties of cassava starch films and their relation to plasticizing effect. Carbohydrate Polymers, Barking, v.60, p.283-289, 2005.

SALAME, M. Barrier polymers. In: BAKER, M. The Wiley encyclopedia of packaging technology. New York: Wiley, 1986. p.48-54.

SOUZA, R.; ANDRADE, C. Investigação dos processos de gelatinização e extrusão de amido de milho. Polímeros: Ciência e Tecnologia, São Carlos, v.10, n.1, p.24-30, 2000.

SOTHORNVIT, R.; KROCHTA, J. M. Plasticizer effect on mechanical properties of $\mathrm{b}$ - lactoblobulin films. Journal of Food Engineering, Essex, v.50, p.149-155, 2001.

SPIESS, W. E. L., WOLF, W. R. The results of the COST 90 project on water activity. In: JOWITT, R.; ESCHER, F.; HALLSTROM, B.; MEFFERT, H.; SPIESS, W. E. L.; VOS, G. (Ed.) Physical properties of foods. London: Applied Science Publishers, 1993. p.65-91.

VILPOUX, O.; AVEROUS, L. Culturas de tuberoses amiláceas latino americanas.: In: CEREDA, M. P.; VILPOUX, O. (Coord.). Tecnologia, usos e potencialidades de tuberosas amiláceas Latino Americanas. São Paulo: Cargill, 2003. v.3, p.500-530.

WURZBURG, O. B. Cross-linking starches. In: WURZBURG, O. B. Modified Starches: properties and uses. Boca Raton: CRC Press, 1986. p.41-53.

YOUNG, H. Fractionation of starch. In: WHISTLER, R. L.; BeMILLER, J. N.; PASCHALL, E. F. (Ed). Starch chemistry and technology. 2.ed. Orlando: Academic Press, 1984. p.249-283. 